\title{
Generalizing about Genre: New Conceptions of an Old Concept
}

\section{Amy J. Devitt}

Our field has become riddled with dichotomies that threaten to undermine our holistic understanding of writing. Form and content (and the related form and function, text and context), product and process, individual and society-these dichotomies too often define our research affiliations, our pedagogies, and our theories. If we are to understand writing as a unified act, as a complex whole, we must find ways to overcome these dichotomies. Recent conceptions of genre as a dynamic and semiotic construct illustrate how to unify form and content, place text within context, balance process and product, and acknowledge the role of both the individual and the social. This reconception of genre may even lead us to a unified theory of writing.

The most recent understandings of genre derive from the work of several significant theorists working with different agendas and from different fields: from literature (M. M. Bakhtin, Tzvetan Todorov, Jacques Derrida), linguistics (M. A. K. Halliday, John Swales), and rhetoric (Carolyn Miller, Kathleen Jamieson). However, this work has not yet widely influenced how most scholars and teachers of writing view genre. Our reconception will require releasing old notions of genre as form and text type and embracing new notions of genre as dynamic patterning of human experience, as one of the concepts that enable us to construct our writing world. Basically, the new conception of genre shifts the focus from effects (formal features, text classifications) to sources of those effects. To accommodate our desires for a reunified view of writing, we must shift our thinking about genre from a formal classification system to a rhetorical and essentially semiotic social construct. This article will explain the new conception of genre that is developing and will suggest some effects of this new conception on our thinking about writing. ${ }^{1}$

\section{The Conventional Conception of Genre}

The common understanding of genre among too many composition scholars and teachers today is that genre is a relatively trivial concept, a classification

\footnotetext{
Amy J. Devitt is associate professor of English at the University of Kansas and, beginning in January 1994, Director of Freshman-Sophomore English. She teaches courses in composition theory, writing, and the English language. Her publications include Standardizing Written English and articles on genre and professional writing. She is currently completing a book manuscript, Writing Genres.
} 
system deriving from literary criticism that names types of texts according to their forms. Viewed in this way, genre is not only a rather trivial concept but also a potentially destructive one, one that conflicts with our best understandings of how writing, writers, and readers work, one that encourages the dichotomies in our field.

Treating genre as form requires dividing form from content, with genre as the form into which content is put; but we have largely rejected this container model of meaning in favor of a more integrated notion of how meaning is made: "Form and content in discourse are one," as Bakhtin writes ("Discourse" 259). Similarly, treating genre as form and text type requires binding genre to a product perspective, without effect on writing processes or, worse yet, inhibiting those processes. As a product-based concept, in fact, this view of genre seems to have more to do with reading than with writing (as attested to by the frequency of genre interpretations among literary critics). Finally, a formal view of genre exaggerates one of the most troubling current dichotomies, that between the individual and the group or society. It makes genre a normalizing and static concept, a set of forms that constrain the individual; genuine writers can distinguish themselves only by breaking out of those generic constraints, by substituting an individual genius for society's bonds.

Though this conventional conception of genre contradicts our best knowledge of how writing works, it has a long history and is not so easily discarded. Formalisms in general have sustained much of the work in linguistics, rhetoric, and literature in the past, the fields out of which genre theories have developed. Not surprisingly, then, most genre theories in the past have been concerned with classification and form, with describing the formal features of a particular genre, describing the embodiment of a genre in a particular work, or delineating a genre system, a set of classifications of (primarily literary) texts. The emphasis on classification can be traced back to the followers of Aristotle, who turned his initial treatment in the Poetics of the epic, tragedy, and comedy into an infinitely modifiable classification scheme. The rhetorical division of discourse into epideictic, judicial, and deliberative can be seen as a similar classification system, one still in use by some today. Other writers propose broader or narrower schemes of text types: literature and nonliterature; narrative and nonnarrative; narrative, exposition, argument, description; the lyric, the sonnet; the Petrarchan sonnet. Whether called genres, subgenres, or modes, whether comprehensive or selective, whether generally accepted or disputed, these systems for classifying texts focus attention on static products.

The efforts spent on devising a classification scheme may be time well spent for some purposes: for supporting or elaborating an interpretation of literature (that literature's import is its effect on readers, for example, or that all literature tells stories), or, to use Anne Freadman's examples (106), for developing a filing system, a library classification system, or disciplinary divisions within a university. For our purposes, perhaps it is enough to agree with Todorov that "We do not know just how many types of discourse there are, but we shall readily agree 
that there are more than one" (9). Or, along with Miller, perhaps we can accept that "the number of genres current in any society is indeterminate and depends upon the complexity and diversity of the society" (163). Understanding genre requires understanding more than just classification schemes; it requires understanding the origins of the patterns on which those classifications are based. As I. R. Titunik comments in summarizing P. M. Medvedev's ideas about genre, "Genre is not that which is determined and defined by the components of a literary work or by sets of literary works, but that which, in effect, determines and defines them" (175).

Once our attention shifts to the origins of genres, it also shifts away from their formal features. Traditional genre study has meant study of the textual features that mark a genre: the meter, the layout, the organization, the level of diction, and so on. Where literary criticism has delineated its invocation to the muse and its fourteen-line sonnet, composition has delineated its fiveparagraph theme, the inverted-triangle introductory paragraph, the division into purpose, methods, results, and discussion of the lab report, and the you-attitude in the business letter. Certainly, such formal features are the physical markings of a genre, its traces, and hence may be quite revealing. In merging form and content, we do not wish to discard the significance of form in genre (see Coe, "Apology"). But those formal traces do not define or constitute the genre (see Freadman 114). Historical changes in generic forms argue against equating genre with form; note the formal changes in what we call a poem, for example, or in the familiar letter. The forms may change but the generic label stays the same. Distinguishing definitive from insignificant forms has proven troublesome, perhaps possible only after the fact. More importantly, equating genre with form is tenable only within the container model of meaning. By integrating form and content within situation and context, recent work in genre theory makes genre an essential player in the making of meaning.

To begin seeing how much more than classification or textual form genre comprehends, consider what we know when, as readers, we recognize the genre of a text. Based on our identification of genre, we make assumptions not only about the form but also about the text's purposes, its subject matter, its writer, and its expected reader. If I open an envelope and recognize a sales letter in my hand, I understand that a company will make a pitch for its product and want me to buy it. Once I recognize that genre, I will throw the letter away or scan it for the product it is selling. If, in a different scenario, I open an envelope and find a letter from a friend, I understand immediately a different set of purposes and a different relationship between writer and reader, and I respond/read accordingly. What I understand about each of these letters and what I reflect in my response to them is much more than a set of formal features or textual conventions. Our theory of genre, therefore, must allow us to see behind particular classifications (which change as our purposes change) and forms (which trace but do not constitute genre). Genre entails purposes, participants, 
and themes, so understanding genre entails understanding a rhetorical and semiotic situation and a social context.

\section{New Conceptions of Genre}

To develop our new genre theory, we begin with rhetorical situation and expand it to encompass a semiotic situation and social context. One major strain of recent genre theory which connects genre to purposes, participants, and themes derives from the notion of genre as response to recurring rhetorical situation. In particular, Miller defines genres as "typified rhetorical actions based in recurrent situations" (159). Although potentially deriving from Aristotle or Burke, the connection of genre to rhetorical situation has been most frequently drawn from the 1968 work of Lloyd Bitzer. In his elaborate exploration of rhetorical situation, Bitzer refers to what happens when situations recur:

Due to either the nature of things or convention, or both, some situations recur.... From day to day, year to year, comparable situations occur, prompting comparable responses; hence rhetorical forms are born and a special vocabulary, grammar, and style are established.... The situation recurs and, because we experience situations and the rhetorical response to them, a form of discourse is not only established but comes to have a power of its own - the tradition itself tends to function as a constraint upon any new response in the form. (13)

Genres develop, then, because they respond appropriately to situations that writers encounter repeatedly. In principle, that is, writers first respond in fitting ways and hence similarly to recurring situations; then, the similarities among those appropriate responses become established as generic conventions. In practice, of course, genres already exist and hence already constrain responses to situations. Genre's efficiency and appropriateness appear clearly in a relatively fixed genre like the lab report: its particular purposes and reader's needs can best be met by its formal features - such as a quick statement of purpose or separate methods and results sections. If all writers of lab reports use these forms, then all lab reports will respond in some appropriate ways to the needs of their situation. Even a more loosely defined genre reveals the appropriateness of generic conventions to situation. The opening of a letter to a friend, for example, just like all our everyday greetings, signals affection and maintains contact, whether the standard "Hi! How are you?" or a more original nod to the relationship. The features that genres develop respond appropriately to their situations.

If each writing problem were to require a completely new assessment of how to respond, writing would be slowed considerably. But once we recognize a recurring situation, a situation that we or others have responded to in the past, our response to that situation can be guided by past responses. Genre, thus, depends heavily on the intertextuality of discourse. As Bakhtin points out in his 
important essay on speech genres, a speaker "is not, after all, the first speaker, the one who disturbs the eternal silence of the universe" (69). The fact that others have responded to similar situations in the past in similar ways-the fact that genres exist-enables us to respond more easily and more appropriately ourselves. Knowing the genre, therefore, means knowing such things as appropriate subject matter, level of detail, tone, and approach as well as the usual layout and organization. Knowing the genre means knowing not only, or even most of all, how to conform to generic conventions but also how to respond appropriately to a given situation.

This straightforward connection of genre to recurring situation begins but does not complete our understanding of genre's origins, for recent theory has expanded the notion of situation. Bitzer's definition of the rhetorical situation has come under attack (see, for example, Vatz; Consigny), and his requirement of a narrowly defined rhetorical exigence as a main component of situation has been troublesome for more wide-ranging composition theory. Based on a fuller range of language behavior, $\mathrm{B}$. Malinowski's concepts of context of situation and context of culture have been developed by M. A. K. Halliday and others (see, especially, Halliday and Hasan), and this conception offers perhaps the best contemporary understanding of situation. Specifically, as Halliday defines it, situation consists of a field (roughly, what is happening), a tenor (who is involved), and a mode (what role language is playing) (31-35). Those components of situation determine what Halliday calls "register," essentially the linguistic equivalent to what I and many of his followers, including Hasan, have called "genre." Like so many other important concepts in Halliday's system, register/genre is a semantic as well as functional concept. He defines it as "the configuration of semantic resources that the member of a culture typically associates with a situation type. It is the meaning potential that is accessible in a given social context" (111). Halliday's definition associates genre/register with situation type and the making of meaning, the most important elements of our reconception of genre so far. It keeps genre as a semantic and functional concept.

Even with a more comprehensive definition of situation, one problem remains with our treatment of genre as response to recurring situation: where does the "situation" come from? In light of recent nonfoundational philosophy and social construction, I would suggest that our construction of genre is what helps us to construct a situation. Genre not only responds to but also constructs recurring situation.

Context, often seen as the larger frame of situation, has long been a troubling concept for linguists and rhetoricians because, among other reasons, it is difficult to specify what context includes. Not everything about the surrounding environment (the temperature, what is happening in the next block) is relevant for the language use being considered, and some things outside the surrounding environment (potential readers, previous texts) are relevant. The concepts of context of situation and context of culture were devised in part to deal with this 
problem of framing. Yet, if the context of situation is not a physical fact of the surrounding environment, as it clearly is not, where does it come from? Today's answer would be that writers and readers construct it. Halliday and Hasan come close to this perspective when they write, "Any piece of text, long or short, spoken or written, will carry with it indications of its context. . . This means that we reconstruct from the text certain aspects of the situation, certain features of the field, the tenor, and the mode. Given the text, we construct the situation from it" (38). In fact, the situation may exist only as writers and readers construct it. As Miller writes, "Situations are social constructs that are the result, not of 'perception,' but of 'definition"” (156), or what Halliday would call semiotic structures. Even more clearly, the recurrence of situation cannot be a material fact but rather what Miller calls "an intersubjective phenomenon, a social occurrence" (156).

We do not construct the situation directly through the text, however; rather, we reach the situation through the genre. Since genre responds to recurring situation, a text's reflection of genre indirectly reflects situation. Thus the act of constructing the genre- of creating or perceiving the formal traces of a genreis also the act of constructing the situation. As discussed earlier, when we as readers recognize the genre of a particular text, we recognize, through the genre, its situation. Like readers, writers also construct situation by constructing genre. A writer faced with a writing task confronts multiple contexts and must define a specific context in relation to that task (teachers tells writers to "figure out who your audience is" or "state your purpose"). By selecting a genre to write in, or by beginning to write within a genre, the writer has selected the situation entailed in that genre. The assignment may ask for a letter to the editor, but the writer who begins with an inverted-triangle introduction is still writing for the teacher.

Writers and readers may, of course, mix genres and situations and may use genres badly. Consider, for example, what happens when writers or readers match genre and situation differently. A writer may try to vary the situationsay by treating the audience as a friend in a formal scholarly article-but the readers will likely note a change in the genre (either noting a flawed text that violates the genre or concluding that the writer is changing the genre). Similarly, a writer who shifts genre in the middle of a text causes confusion for the reader, not because the reader cannot label the genre but because the reader cannot be sure of the writer's purpose or the reader's role-cannot be sure of the situation. For a final example, a reader who "misreads" a text's genre-who reads "A Modest Proposal" as a serious proposal, say-most significantly misreads the situation as well. Genre and situation are so linked as to be inseparable, but it is genre that determines situation as well as situation that determines genre.

If genre not only responds to but also constructs recurring situation, then genre must be a dynamic rather than static concept. Genres construct and respond to situation; they are actions (see Miller). As our constructions of situations change and new situations begin to recur, genres change and new 
genres develop. Since situation is inherently a social as well as rhetorical concept, genres change with society, as Gunther Kress explains:

If genre is entirely imbricated in other social processes, it follows that unless we view society itself as static, then neither social structures, social processes, nor therefore genres are static. Genres are dynamic, responding to the dynamics of other parts of social systems. Hence genres change historically; hence new genres emerge over time, and hence, too, what appears as 'the same' generic form at one level has recognizably distinct forms in differing social groups. (42)

Dynamic genres are also fluid rather than rigid, are possible responses that writers choose and even combine to suit their situations. "The wealth and diversity of speech genres are boundless," Bakhtin writes, "because the various possibilities of human activity are inexhaustible, and because each sphere of activity contains an entire repertoire of speech genres that differentiate and grow as the particular sphere develops and becomes more complex" ("Problem" 60). The connection to social spheres and groups has led some to tie genre to the constructions of a discourse community, a promising connection developed most fruitfully by John Swales in his 1990 book on genre. Whether through discourse communities or some other social frame, genre must respond dynamically to human behavior and social changes.

One concern that has been raised in the past is that genre can become deterministic. Especially for such a social view of genre as this, some worry that the individual writer no longer matters. The split between the individual and society, however, is another false dichotomy that our new conception of genre can help to resolve. Denigrating genre became popular with the glorification of the individual, a romantic strain in literary criticism that considers genre and previous texts as constraints, as something that great writers must transcend, as producing anxiety for the writer. Yet an opposing trend has seen the inherent intertextuality of all writing, has discerned that T. S. Eliot's "historical sense" enriches rather than constrains the individual writer. Writers work creatively within the frame of past texts and given genres just as they work within the frame of a given language.

It is indeed true that "the single utterance, with all its individuality and creativity, can in no way be regarded as a completely free combination of forms of language" (Bakhtin, "Problem" 81). Genres are existing and somewhat normative constructs, some more rigid than others, but so too are all language forms. All language constrains the individual to the extent that language is an existing set of forms; however, as Bakhtin points out, "Speech genres are much more changeable, flexible, and plastic than language forms are" ("Problems" 80). Language and genre constrain but do not eliminate the individual writer. As constituents of society, individuals create language and create genre. Being part of society enables individuals to change society, and hence to change genres, for genres, as Volosinov/Bakhtin writes, "exhibit an extraordinary sensitivity to all fluctuations in the social atmosphere" (20). Individuals may, of course, combine 
different genres or may "violate" the norms of an existing genre, thereby confirming that genre's existence and potentially changing it. (See discussions in Todorov, Derrida, and Freadman.) Working within existing genres as well, individuals choose and create: even the most rigid genre requires some choices, and the more common genres contain substantial flexibility within their bounds. Ultimately, as Frances Christie writes in her article "Genres as Choice," "Capacity to recognise, interpret and write genres is capacity to exercise choice" (32). Individuals choose within linguistic and generic conventions, and they create and recreate the society that those conventions reflect. Although genre thus is a social concept and construct, it also clarifies the nature of individual choices. Again, genre proves the dichotomy false.

In sum, genre is a dynamic response to and construction of recurring situation, one that changes historically and in different social groups, that adapts and grows as the social context changes. This new conception of genre has managed to overcome several dichotomies in our understanding of language use and writing. In reuniting genre and situation, it reunites text and context, each constructing and responding to the other in a semiotic interchange. Form and function are both inherent in genre, as are form and content. Miller explains that genre semiotically fuses the syntactic, semantic, and pragmatic. Sigmund Ongstad has genre fusing the form, content, and function. Genre is both the product and the process that creates it. Genre is what Bakhtin calls "the whole of the utterance" ("Problem" 60), a unity and a unifier.

This new conception of genre helps us to see how individual writers and individual texts work, then, by removing us one level from the individual and particular. Genre is an abstraction or generality once removed from the concrete or particular. Not as abstract as Saussurian notions of langue or language system, genre mediates between langue and parole, between the language and the utterance. Not as removed as situation, genre mediates between text and context. Not as general as meaning, genre mediates between form and content. Genre is patterns and relationships, essentially semiotic ones, that are constructed when writers and groups of writers identify different writing tasks as being similar. Genre constructs and responds to recurring situation, becoming visible through perceived patterns in the syntactic, semantic, and pragmatic features of particular texts. Genre is truly, therefore, a maker of meaning.

\section{Implications}

So what does such a reconception of genre do for us as composition scholars and teachers? For our scholarship, a new conception of genre might fill some significant gaps in our existing theories of writing. ${ }^{2}$ We have already seen how genre can help us to reintegrate several dichotomies in our view of writing. Most particular to genre theory might be the better reintegration of form with content and of text with context, the former a longstanding marriage we still 
struggle to explain to others, the latter a more recent split whose divorce we are just beginning to contest. Can we speak of context apart from text? Contexts are always textualized. Through genre we can speak of both, as do many scholars who study particular genres in particular communities (such as Bazerman and Myers, in their studies of the experimental article in science and articles in biology, respectively). Studies of particular genres and of particular genre sets (as, for example, the research-process genres in Swales, or the genre sets of tax accountants in Devitt, "Intertextuality") can reveal a great deal about the communities which construct and use those genres, and studies of particular texts within those genres can reveal a great deal about the choices writers make.

The reintegration of product and process that this new genre theory enables can clarify the value of studying products or texts, but it also can contribute to our understanding of process and text-making. Some of the longstanding (and often unspoken) questions about writing processes can be addressed through considering genre's role. Two such questions will illustrate: Where do writers' goals come from? How do writers know what to change when they are revising?

One of the classic articles on writing processes, Linda Flower and John Hayes's 1981 article "A Cognitive Process Theory of Writing," might have had a different emphasis had a better understanding of genre been well shared when it was written. Flower and Hayes concentrated in part on how writers generate and regenerate goals. In one paragraph, they acknowledge a small role for genre:

but we should not forget that many writing goals are well-learned, standard
ones stored in memory. For example, we would expect many writers to
draw automatically on those goals associated with writing in general, such
as, "interest the reader," or "start with an introduction," or on goals asso-
ciated with a given genre, such as making a jingle rhyme. These goals will
often be so basic that they won't even be consciously considered or ex-
pressed. And the more experienced the writer the greater this repertory of
semi-automatic plans and goals will be. (381)

With our new conception of genre, we would agree that "well-learned, standard" goals are "so basic that they won't even be consciously considered or expressed," and that more experienced writers will be well-stocked with "semiautomatic plans and goals." However, rather than being uninteresting because unconscious and rather than being trivial ("such as making a jingle rhyme"), these "basic" and "well-learned" generic goals may be the stuff of which all writing goals (at least partly) are made. Bakhtin ("Problem"), for example, describes "primary" speech genres, which are the culturally established building blocks of more complex "secondary" genres, most written genres being secondary genres. To understand the situational and social constructs behind such primary and secondary genres may be to understand more deeply the goals that writers have and the forces at work in their generation and regeneration. Understanding writing processes, then, must include understanding generic goals: what they are-the historical, community, and rhetorical forces that shape them-how writers learn them, and how writers use them. 
Similarly, a better understanding of genre may help us understand better how writers know when and what to revise. As an important part of revision, scholars have described the perception of dissonance, between intention and text or between intention and execution (see, for example, Sommers; and Flower and Hayes). But James Reither asserts that "Composition studies does not seriously attend ... to the knowing without which cognitive dissonance is impossible" (142). A large part of that "knowing" must be knowing genres. How, Flower and her coauthors ask, "can we say that a writer detects a dissonance or a failed comparison between text and intention when the second side of the equation, an 'ideal' or 'correct' or intended text doesn't exist-when there is no template to 'match' the current text against?" (27). Genre might provide at least part of that template, might provide at least part of the writer's notion of the ideal text. If a writer has chosen to write a particular genre, then the writer has chosen a template, a situation and an appropriate reflection of that situation in sets of forms. ${ }^{3}$ In revising, a writer may check the situation and forms of the evolving text against those of the chosen genre: where there is a mismatch, there is dissonance. Genre by no means solves the problem of determining why writers revise what they do; but without genre a complete solution to the problem is impossible.

As these brief discussions of goals and dissonance illustrate, studies of writing processes and cognitive perspectives on writing must take genre into account. In fact, researchers most interested in the cognition of individual writers can make essential contributions to genre theory by studying how writers learn and use a variety of genres. The creation, transmission, and modification of genres can be studied further by those most interested in social and rhetorical perspectives on writing.

As mentioned earlier, many scholars studying nonacademic discourse have used genre as a variable, even as a controlling concept for understanding the community. In my study of tax accountants' writing ("Intertextuality"), for example, understanding the group's values, assumptions, and beliefs is enhanced by understanding the set of genres they use, their appropriate situations and formal traits, and what those genres mean to them. Swales develops the fullest and most complex treatment of genre's relationship to discourse communities in his important book Genre Analysis. His significant work embedding genre in discourse communities can be extended and developed by others, if we can resolve such discourse-community issues as the nature of the community, overlapping communities, and writers participating in multiple communities. In fact, the same kind of semiotic interchange that is so useful for understanding genre may help us to understand discourse community. Just as genres construct situations and situations construct genres, discourse may construct communities and communities construct discourse. Thus, rather than looking at human membership to define community, perhaps discourse membership - that is, genre sets-can better define the nature and constitution of a discourse community, just as the community better defines the nature of the discourse. 
As someone who has been working on understanding genre for many years, I, of course, see the potential benefits of genre in virtually every article or book I read on composition theory and teaching. Studies of the relationship between reading and writing need to acknowledge that genre connects readers and writers, both their products and their processes, and need to investigate how their interpretations of genre vary (or do not). Research on assessment and on assignments needs to consider the power of differing generic demands to influence results. Judith A. Langer, for example, found that "genre distinctions were stronger than grade distinctions in their effects on student writing" (167). Researchers of basic writing need to go beyond the forms of academic genres to see their situational constructs, with ideologies and roles that may pose conflicts for some basic writers. A study of Athabaskans, a group of Alaskan Indians, discussed by Michael B. Prince, found that learning to write a new genre "implied cultural and personal values that conflicted with pre-existing patterns of thought and behavior" (741). Christie goes so far as to assert that "Those who fail in schools are those who fail to master the genres of schooling: the ways of structuring and of dealing with experience which schools value in varying ways" ("Language" 24).

Although it may be premature to outline full programs, many powerful revolutions in our teaching might develop from a better understanding of genre. Teachers of writing need to discover how to teach novices the situations and forms of the genres they will need without undermining the wholeness of a genre. Aviva Freedman's research suggests that some novices may learn to write particular genres without explicit instruction, even ignoring explicit feedback. Richard M. Coe, on the other hand, argues for making all such models conscious "so that we may use them critically instead of habitually" ("Rhetoric" 11). Research needs to be done to discover the most effective techniques of translating our better genre theory into better writing instruction and thence into practice.

Even as we await more substantial knowledge of how novices can best learn and use genres, we can use the new conception of genre to improve our teaching, especially our diagnosis and treatment of students' problems. Since the genre constructs the situation, students will not be able to respond appropriately to assigned situations unless they know the appropriate genre. What we often diagnose as ignorance of a situation or inability to imagine themselves in another situation may in fact be ignorance of a genre or inability to write a genre they have not sufficiently read: they may feel great love but be unable to write a love sonnet. Conversely, since genre and situation are mutually constructive, what we diagnose as inability to write a particular genre may in fact be unfamiliarity with the genre's situation: students may know the genre of letters to the editor in a superficial way, but if they have never felt the need to write such a letter-if they have never experienced the situation-they may be incapable of writing one that appropriately responds to that situation. When we create assignments and as we evaluate responses to them, we must consider both their situational and generic demands. 
Once we acknowledge genre as more than a formal constraint on writers but rather an essential component of making meaning, we might find it influencing other notions that we teach. Prewriting and revising processes probably differ for different genres, since those genres represent different situations, including constraints. Certainly, teaching students how to define their audiences and purposes would change under a new notion of genre since it would be clear that selecting a genre would automatically narrow the possibilities for audience and purpose; conversely, wanting to address a particular audience and purpose constrains one's choice of genre. Newly conceived genres should, of course, serve the final death notice to the modes as a classification system. Even usage standards might be most clearly explained through genre, as sets of language forms that are a small part of the larger conventions of some genres deriving from particular situations. Depending on our individual theories of writing and teaching, we may still value originality above all, or self-expression, or clarity, or correctness; but we may no longer ignore the fact that genre operates as a force on our students as they try to meet our expectations.

In spite of what my genre-colored glasses show me, genre may not be the answer to all of our dilemmas in composition theory and teaching. But only by ignoring what writers themselves recognize can we ignore the significance of genre. This new theory of genre reveals and explains the centrality of genre to writing, its importance to understanding how writers and writing work. It also suggests how we might develop an integrated, unified theory of writing. With a unified theory of genre, we can reintegrate text and context, form and content, process and product, reading and writing, individual and social. In the end, genre's ability to capture both form and situation, both constraint and choice, may capture the essence of writing as well.

\section{Notes}

1. This article was supported in part by the University of Kansas general research allocation \#3629-0038. I would like to thank those who gave me many helpful comments on an earlier draft of this article: Richard Coe, Aviva Freedman, James Hartman, Michael Johnson, Pat McQueeney, and the anonymous readers for CCC.

2. See Devitt, "Genre" for a discussion of the implications of a new genre theory for the study of language.

3. The notion of genre as template might be indebted to schemata theory and script theory. These theories, as rich as they are for understanding the complexities of human conventions, may have been a necessary precursor to this understanding of generic conventions.

\section{Works Cited}

Bakhtin, M. M. "Discourse in the Novel." The Dialogic Imagination: Four Essays by M. M. Bakhtin. Ed. Michael Holquist. Trans. Caryl Emerson and Michael Holquist. Austin and London: U of Texas P, 1981. 259-422. 
"The Problem of Speech Genres." Speech Genres and Other Late Essays. Ed. Caryl Emerson and Michael Holquist. Trans. Vern W. McGee. Austin: U of Texas P, 1986. 60-102.

Bazerman, Charles. Shaping Written Knowledge: The Genre and Activity of the Experimental Article in Science. Madison: U of Wisconsin P, 1988.

Bitzer, Lloyd F. “The Rhetorical Situation.” Philosophy and Rhetoric 1 (Winter 1968): 1-14.

Campbell, Karlyn Kohrs, and Kathleen Hall Jamieson, eds. Form and Genre: Shaping Rhetorical Action. Falls Church: Speech Communication Association, 1978.

Christie, Frances. "Genres as Choice." Reid 22-34.

"Language and Schooling." Language, Schooling, and Society. Ed. Stephen N. Tchudi. Upper Montclair: Boynton/Cook, 1984. 21-40.

Coe, Richard M. "An Apology for Form; or, Who Took the Form Out of the Process?" College English 49 (Jan. 1987): 13-28.

—. "Rhetoric 2001." Freshman English News 3.1 (Spring 1974): 1-13.

Consigny, Scott. "Rhetoric and Its Situations." Philosophy and Rhetoric 7 (Summer 1974): 175-86.

Derrida, Jacques. “The Law of Genre." Trans. Avital Ronell. Critical Inquiry 7 (Autumn 1980): 55-82.

Devitt, Amy J. "Genre as Textual Variable: Some Historical Evidence from Scots and American English." American Speech 64 (Winter 1989): 291-303.

_. "Intertextuality in Tax Accounting: Generic, Referential, and Functional." Textual Dynamics of the Professions: Historical and Contemporary Studies of Writing in Professional Communities. Ed. Charles Bazerman and James Paradis. Madison: U of Wisconsin P, 1991. 336-57.

Flower, Linda, and John R. Hayes. "A Cognitive Process Theory of Writing." College Composition and Communication 32 (Dec. 1981): 365-87.

Flower, Linda, et al. "Detection, Diagnosis, and the Strategies of Revision." College Composition and Communication 37 (Feb. 1986): 16-55.

Freadman, Anne. "Anyone for Tennis?" Reid 91-124.

Freedman, Aviva. "Learning to Write Again: Discipline-Specific Writing at University." Carleton Papers in Applied Language Studies 4 (1987): 95-115.

Halliday, M. A. K. Language as Social Semiotic: The Social Interpretation of Language and Meaning. London: Edward Arnold, 1978.

Halliday, M. A. K., and Ruqaiya Hasan. Language, Context, and Text: Aspects of Language in a Social-Semiotic Perspective. 2nd ed. Oxford: Oxford UP, 1989.

Jamieson, Kathleen "Antecedent Genre as Rhetorical Constraint." Quarterly Journal of Speech 61 (Dec. 1975): 406-15.

Kress, Gunther. “Genre in a Social Theory of Language: A Reply to John Dixon.” Reid 35-45.

Langer, Judith A. "Children's Sense of Genre: A Study of Performance on Parallel Reading and Writing Tasks." Written Communication 2 (Apr. 1985): 157-87.

Malinowski, B. "The Problem of Meaning in Primitive Languages." Supplement I. The Meaning of Meaning: A Study of the Influence of Language upon Thought and of the Science of Symbolism. C. K. Ogden and I. A. Richards. 10th ed. New York: Harcourt and London: Routledge, 1952. 296-336.

Miller, Carolyn R. "Genre As Social Action." Quarterly Journal of Speech 70 (May 1984): 151-67.

Myers, Greg. Writing Biology: Texts in the Social Construction of Scientific Knowledge. Madison: U of Wisconsin P, 1990. 
Ongstad, Sigmund. "The Definition of Genre and the Didactics of Genre." Rethinking Genre Colloquium. Ottawa, April 1992.

Prince, Michael B. "Literacy and Genre: Toward a Pedagogy of Mediation." College English 51 (Nov. 1989): 730-49.

Reid, Ian, ed. The Place of Genre in Learning: Current Debates. Deakin University: Centre for Studies in Literary Education, 1987.

Reither, James A. "Writing and Knowing: Toward Redefining the Writing Process." College English 47 (Oct. 1985): 620-28. Rpt. in The Writing Teachers'Sourcebook. Ed. Gary Tate and Edward P. J. Corbett. 2nd ed. New York: Oxford UP, 1988. 140-48.

Sommers, Nancy. "Revision Strategies of Student Writers and Experienced Adult Writers." College Composition and Communication 31 (Dec. 1980): 378-88.

Swales, John M. Genre Analysis: English in Academic and Research Settings. Cambridge: Cambridge UP, 1990.

Titunik, I. R. "The Formal Method and the Sociological Method (M. M. Baxtin, P. N. Medvedev, V. N. Volosinov) in Russian Theory and Study of Literature." Volosinov [Bakhtin] 175-200.

Todorov, Tzvetan. Genres in Discourse. Trans. Catherine Porter. Cambridge: Cambridge UP, 1990.

Vatz, Richard. "The Myth of the Rhetorical Situation." Philosophy and Rhetoric 6 (Summer 1973): 154-61.

Volosinov, V. N. [M. M. Bakhtin]. Marxism and the Philosophy of Language. Trans. Ladislav Matejka and I. R. Titunik. Cambridge and London: Harvard UP, 1986.

The National Council of Teachers of English joins the NCTE Black Caucus in sponsoring the FifTh National African American Read-In Chain on Sunday, February 6, 1994, at 4:00 p.m. EST, and on Monday, February 7, 1994, for schools. Schools, community and professional organizations, businesses, churches, libraries, bookstores, and interested citizens are urged to make literacy a significant part of Black History Month by hosting and coordinating Read-Ins in their communities. For more information about this and future Read-Ins, contact Dr. Jerrie C. Scott, Central State University, Urban Literacy-Lower Library, Wilberforce, OH 45384 (513-376-6535); or Dr. Sandra E. Gibbs, NCTE Special Programs, 1111 W. Kenyon Road, Urbana, IL 61801-1096 (217-328-3870, Ext. 230). 